Check for updates

Cite this: Phys. Chem. Chem. Phys., 2018, 20, 12200

Received 7th December 2017, Accepted 4th March 2018

DOI: $10.1039 / c 7 c p 08220 g$

rsc.li/pccp

\section{Dihydrogen vs. hydrogen bonding in the solvation of ammonia borane by tetrahydrofuran and liquid ammonia $\dagger$}

\author{
David J. Ingram, (DD ab Thomas F. Headen, (D)*c Neal T. Skipper, ${ }^{a d}$ \\ Samantha K. Callear, ${ }^{c}$ Matthew Billing ${ }^{b}$ and Andrea Sella ${ }^{b}$
}

\begin{abstract}
The solvation structures of two systems rich in hydrogen and dihydrogen bonding interactions have been studied in detail experimentally through neutron diffraction with hydrogen/deuterium isotopic substitution. The results were analysed by an atomistic Monte Carlo simulation employing refinement to the experimental scattering data. The systems studied were the hydrogen storage material ammonia borane $\left(\mathrm{NH}_{3} \mathrm{BH} \mathrm{H}_{3}, \mathrm{AB}\right)$ dissolved in tetrahydrofuran (THF), and liquid ammonia $\left(\mathrm{NH}_{3}\right)$, the latter in which $A B$ shows unusually high solubility (260 $\mathrm{g} \mathrm{AB}$ per $100 \mathrm{~g} \mathrm{NH}_{3}$ ) and potential regeneration properties. The full orientational and positional manner in which $A B-A B, A B-T H F$ and $A B-N_{3}$ pairs interact with each other were successfully deciphered from the wide $Q$-range total neutron scattering data. This provided an unprecedented level of detail into such highly (di)hydrogen bonding solute-solvent interactions. In particular this allowed insight into the way in which $\mathrm{H}-\mathrm{B}$ acts as a hydrogen bond acceptor. The (di)hydrogen bonding was naturally determined to dictate the intermolecular interactions, at times negating the otherwise expected tendency for polar molecules to align themselves with anti-parallel dipole moments. Several causes for the extreme solubility of $A B$ in ammonia were determined, including the ability of ammonia to (di)hydrogen bond to both ends of the $A B$ molecule and the small size of the ammonia molecule relative to $A B$ and THF. The $A B B-H$ to ammonia $H$ dihydrogen bond was found to dominate the intermolecular interactions, occurring almost three times more often than any other hydrogen or dihydrogen bond in the system. The favourability of this interaction was seen on the bulk scale by a large decrease in AB clustering in ammonia compared to in the dihydrogen bond-less THF.
\end{abstract}

\section{Introduction}

A classic example of an important intermolecular interaction is the hydrogen bond. ${ }^{1}$ This follows the pattern $\mathrm{X}-\mathrm{H} \cdots \mathrm{Y}$, where the donor atom $\mathrm{X}$, being more electronegative than hydrogen, causes said hydrogen to possess a partial positive charge. The acceptor, $\mathrm{Y}$, is an atom capable of stabilising this charge, usually taking the form of an atom with a free lone or nonbonding pair of electrons, commonly a nitrogen or oxygen. Hydrogen bonds are common, and influence the properties of

\footnotetext{
${ }^{a}$ Department of Physics \& Astronomy, University College London, Gower Street, London, WC1E 6BT, UK

${ }^{b}$ Department of Chemistry, University College London, 20 Gower Street, London, WC1H OAJ, UK

${ }^{c}$ ISIS Facility, Rutherford Appleton Laboratory, Chilton, Oxfordshire, OX11 OQX, UK. E-mail: tom.headen@stfc.ac.uk

${ }^{d}$ London Centre for Nanotechnology, University College London, Gower Street, London, WC1E 6BT, UK

$\dagger$ Electronic supplementary information (ESI) available. See DOI: 10.1039/ c7cp08220g
}

molecules as small as water, up to those as large and complex as proteins and DNA.

A somewhat rarer type of intermolecular interaction is dihydrogen bonding. This is quite similar to regular hydrogen bonding in terms of the donor, but the difference lies in that the acceptor is no longer a single atom. A dihydrogen bond instead follows the pattern $\mathrm{X}-\mathrm{H} \cdots \mathrm{H}-\mathrm{Y}$, where the $\mathrm{H}$ bound to $\mathrm{Y}$ possesses a partial negative charge, caused normally by the relatively lower electronegativity of $\mathrm{Y}$. This leads to a weak electrostatic attraction between the two hydrogens involved. Dihydrogen bonds have been observed within transition metal hydrides, playing a role in processes such as proton transfer and $\mathrm{H}_{2}$ evolution. ${ }^{2}$ Dihydrogen bonding has also frequently been observed in main group hydrides, especially those containing boron, where they have been shown to enable stereochemical control of reactions like reduction. ${ }^{3,4}$

Amine-boranes are a family of compounds known to be rich in dihydrogen bonding, owing to the hydridic and protonic natures of the hydrogens bound to boron and nitrogen respectively. Ammonia borane $\left(\mathrm{NH}_{3} \mathrm{BH}_{3}, \mathrm{AB}\right)$ is the simplest amine-borane, 


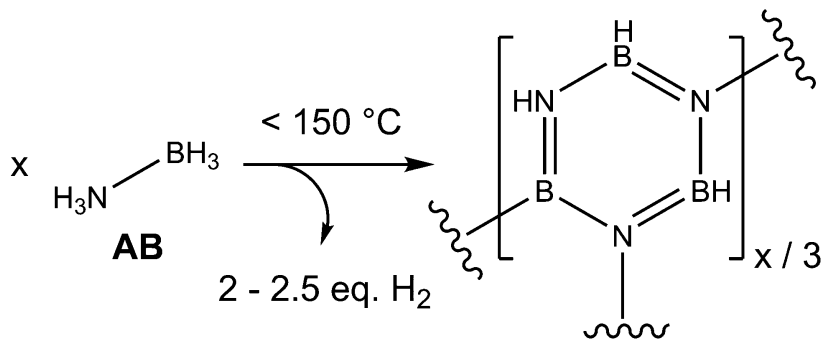

Fig. 1 The thermal dehydrogenation of $A B$ leads to a multitude of unsaturated cyclic products.

and studies of the solid-state structure of $\mathrm{AB}$, both theoretical and experimental, are numerous. ${ }^{5-9}$ In $\mathrm{AB}$, the dihydrogen bonds were distinguished from other intermolecular interactions (such as van der Waals forces) and classified as a type of hydrogen bond using "atoms in molecules" theory. ${ }^{10}$ The $\mathrm{H}_{\mathrm{N}} \cdots \mathrm{H}_{\mathrm{B}}$ dihydrogen bond is responsible for many of the properties of $\mathrm{AB}$, including the high melting point $\left(110-114{ }^{\circ} \mathrm{C}, c f\right.$. the isoelectronic ethane $\left.-182.8^{\circ} \mathrm{C}\right) .{ }^{11}$

$\mathrm{AB}$ has received wide-spread attention due to its potential as an air-stable and safe hydrogen storage material. $\mathrm{AB}$ contains 19.6 wt \% hydrogen, approximately $13-16$ wt $\%$ (2-2.5 eq. $\mathrm{H}_{2}$ per $\mathrm{AB})$ of which can be extracted by heating to mild temperatures $\left(<150{ }^{\circ} \mathrm{C}\right)$ (Fig. 1). The dihydrogen bonds have to be overcome in order for the material to melt, which occurs simultaneously with the onset of hydrogen release. ${ }^{11}$ In addition to these intermolecular interactions, homopolar $\mathrm{H}_{\mathrm{B}} \cdots \mathrm{H}_{\mathrm{B}}$ interactions have been theorised to exist during the dehydrogenation process, due to an isotopic substitution experiment (which observed, for example, $\mathrm{D}_{2}$ on dehydrogenation of $\left.\mathrm{NH}_{3} \mathrm{BD}_{3}\right) .{ }^{12}$

A factor holding back the use of $\mathrm{AB}$ is in the difficulty of recycling the waste material post-dehydrogenation. This waste consists of a variety of partially hydrogenated hexagonal boron nitride-like products. Many attempts have been made to efficiently regenerate $\mathrm{AB}$ waste. ${ }^{13-17}$ A promising one-pot route involves treating the waste with hydrazine in liquid ammonia, which was shown to regenerate an $\mathrm{AB}$ waste surrogate successfully in 24 hours at $40{ }^{\circ} \mathrm{C} .{ }^{14}$ A further curiosity in terms of treating $\mathrm{AB}$ waste surrogates with liquid ammonia was demonstrated by Davis et al., who showed that some Lewis bases (specifically, pyridine and ammonia) were able to scavenge some of the residual high energy $\mathrm{B}-\mathrm{H}$ bonds in the waste and rearrange them to form $\mathrm{BH}_{3}$. If the Lewis base used was ammonia, this led to direct regeneration of some of the waste back into $\mathrm{AB} .^{18}$ $\mathrm{AB}$ also has an extremely high solubility in ammonia (260 g AB per $100 \mathrm{~g} \mathrm{NH}_{3}$ at $298 \mathrm{~K}, c f .25 \mathrm{~g} \mathrm{AB}$ per $100 \mathrm{~g}$ tetrahydrofuran). ${ }^{11}$ This behaviour raises the question of how $\mathrm{AB}$ interacts with ammonia in solution, and has implications for future attempts at the regeneration of $\mathrm{AB}$ waste.

While there have been studies into the dynamics of dihydrogen bonding using IR and NMR spectroscopy, there has not yet to our knowledge been a detailed empirical analysis of the full structural and orientational way in which dihydrogen bonding occurs in solution. ${ }^{19,20}$ Solvation as studied through neutron diffraction is a wide-ranging and active subject with applications in many fields ranging from physical chemistry to biochemistry. ${ }^{21-27}$ In addition to the $\mathrm{AB}$-ammonia interactions, a more fundamental interest in the nature of solvation in such a (di)hydrogen bondrich environment sparks our study of these systems. Insight into the $\mathrm{AB}-\mathrm{AB}$ intermolecular interactions is a further goal for this work. Due to the concurrent release of hydrogen when $A B$ melts, the interactions within molten $\mathrm{AB}$ cannot be directly studied; a concentrated solution of $\mathrm{AB}$ in liquid ammonia, especially considering the structural similarities, is probably the best analogue for studying such a system.

In this paper the solvation structure of $\mathrm{AB}$ in both liquid ammonia and tetrahydrofuran (THF), another common solvent, has been investigated through the use of neutron diffraction. Empirical Potential Structure Refinement (EPSR) was used to analyse the results, and build up a simulation box that could be interrogated to determine the spatial and orientational solvent-solute interactions. ${ }^{28-30}$ Isotopic substitution of both the solvent and solute hydrogens for deuterium was performed to obtain additional, complementary constraints for the data refinement process. The results were compared with those from solid state diffraction and $a b$ initio calculations of dimers, providing important insight into the distribution of dihydrogen bonding structures in the liquid state. A description of the theory behind the neutron diffraction experiments and the EPSR procedure is provided in the ESI. $\dagger$

\section{Results and discussion}

The neutron scattering experiments were performed on 7 samples for $\mathrm{AB}$ in $\mathrm{THF}$ and 3 samples for $\mathrm{AB}$ in $\mathrm{NH}_{3}$ (details in Experimental section). Table 1 shows the seed parameters used for the EPSR simulations, with the atom nomenclature shown in Fig. 2. The Lennard-Jones parameters for $\mathrm{AB}$ were adapted from the CHARMM parameters for methylamine used in Chen et al., as parameters for $\mathrm{AB}$ do not exist to our knowledge. ${ }^{31}$ It is important to mention that the seed potentials are only a starting point, and differences in structural behaviour induced in the simulation would be compensated for by the refinement. The $\mathrm{AB}$ charges were sourced from a Mulliken analysis of $\mathrm{AB}$ itself. ${ }^{32}$ For ammonia, the nitrogen parameters were taken from Gao et al., with the hydrogen values adjusted to match the $\mathrm{AB} \mathrm{N}-\mathrm{Hs} .^{33}$ Finally, the THF parameters were taken from the OPLS all-atom force field. ${ }^{34-38}$

Table 1 EPSR seed parameters used in the simulations

\begin{tabular}{lllr}
\hline Atom label & Epsilon $/ \mathrm{kJ} \mathrm{mol}^{-1}$ & Sigma/A & Charge/e \\
\hline $\mathrm{N}$ & 0.25104 & 3.5458 & -0.9100 \\
$\mathrm{~B}$ & 0.33472 & 3.5458 & -0.2900 \\
$\mathrm{H}_{\mathrm{N}}$ & 0.04184 & 1.5591 & 0.4500 \\
$\mathrm{H}_{\mathrm{B}}$ & 0.16736 & 2.2451 & -0.0500 \\
$\mathrm{~N}_{\mathrm{A}}$ & 0.87900 & 3.3600 & -1.0260 \\
$\mathrm{H}_{\mathrm{A}}$ & 0.04184 & 1.5591 & 0.3420 \\
$\mathrm{O} 1$ & 0.58576 & 2.9000 & -0.4000 \\
$\mathrm{C} 1$ & 0.27614 & 2.5000 & 0.1400 \\
$\mathrm{C} 2$ & 0.27614 & 2.5000 & -0.1200 \\
$\mathrm{H}_{\mathrm{C} 1}$ & 0.12552 & 2.5000 & 0.0300 \\
$\mathrm{H}_{\mathrm{C} 2}$ & 0.12552 & 2.5000 & 0.0600
\end{tabular}



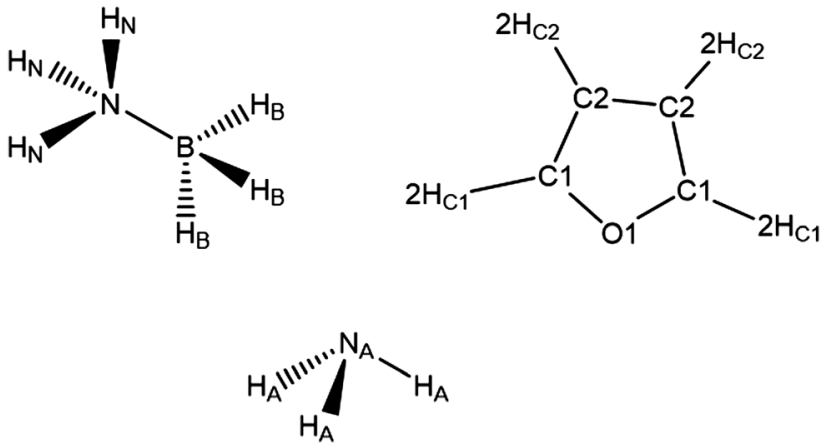

Fig. 2 Atom labels used throughout the analysis of the EPSR simulations of $A B$ dissolved in $\mathrm{THF}$ and liquid ammonia.

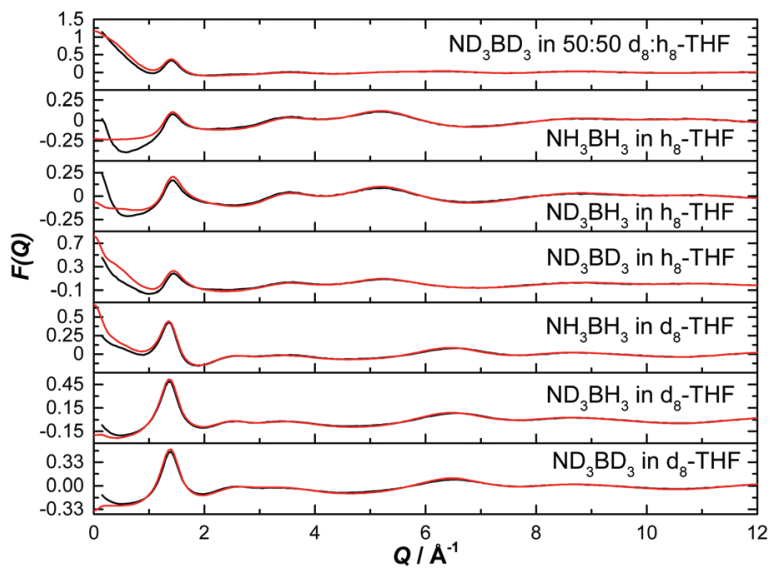

Fig. 3 Diffraction pattern (black) and EPSR fitted structure factor (red) for various isotope combinations of ammonia borane dissolved in THF.

The normalised structure factors for the $\mathrm{AB}$ in $\mathrm{THF}$ and $\mathrm{AB}$ in ammonia experiments are shown in Fig. 3 and 4 respectively, together with the simulated EPSR fits. Scattering for $Q<2 \AA^{-1}$ is dominated by the intermolecular interactions, weighted by each atom's neutron scattering length and concentration. The opposite occurs at high $Q$, with the intramolecular interactions dominant.

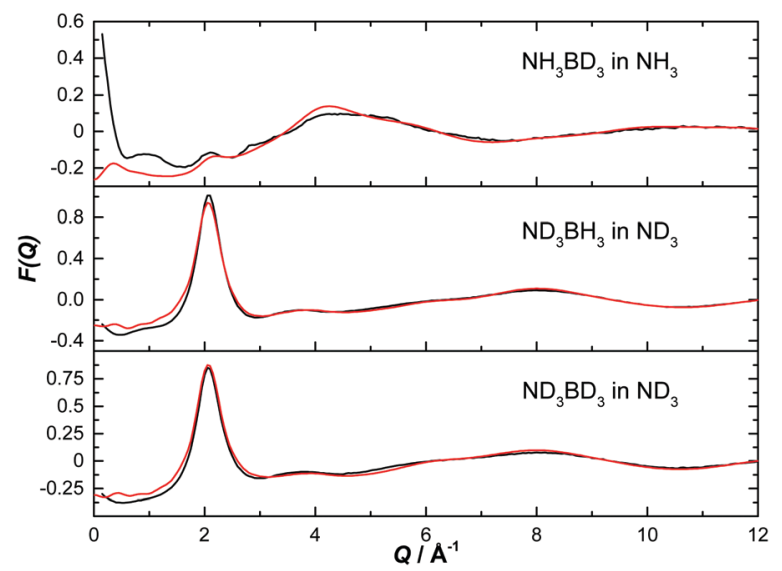

Fig. 4 Diffraction pattern (black) and EPSR fitted structure factor (red) for various isotope combinations of ammonia borane dissolved in ammonia.
The EPSR fits are of good quality, with the deviations at $Q<0.5 \AA^{-1}$ caused most likely by errors in the inelasticity correction, which would explain the larger magnitude in hydrogen (rather than deuterium) rich samples. ${ }^{39,40}$

The Fourier transformation of the total structure factors produces the total radial distribution functions, shown in Fig. S1 and S2 (ESI $\dagger$ ). These show that the intramolecular bond lengths are modelled accurately in our simulations.

More specific structural information can be obtained by looking at the partial radial distribution functions $(g(r), \mathrm{RDF})$ for atom pairs of interest in our systems.

\subsection{Ammonia borane-ammonia borane interactions}

We have used the output of the EPSR simulations to study both hetero- and homopolar interactions between $\mathrm{AB}$ molecules. Given the likelihood for $\mathrm{AB}-\mathrm{AB}$ interactions to be less rigid in solution than in the solid state (and arguably more similar to melted/dehydrogenating $\mathrm{AB}$ ), this allows an understanding of the interactions suggested to exist during dehydrogenation. ${ }^{12}$

Fig. 5 shows the partial RDF for heteropolar $\mathrm{H}_{\mathrm{N}} \cdots \mathrm{H}_{\mathrm{B}}$ and homopolar $\mathrm{H}_{\mathrm{B}} \cdots \mathrm{H}_{\mathrm{B}}$ interactions. The sharp peak at $1.85 \AA$ in the heteropolar function suggests the presence of strong dihydrogen bonding between $\mathrm{AB}$ molecules. This distance is smaller than the sum of the van der Waals radii for two hydrogen atoms (2.4 $⿱$ ) and characteristic of, though slightly shorter than, the dihydrogen bonding present in the solid state $(2.02 \AA) .{ }^{11,20}$ This structural motif appears in both ammonia and THF. In ammonia however, the magnitude of the peak is much lower suggesting $\mathrm{AB}-\mathrm{AB}$ interactions are less numerous (both graphs were normalised to the bulk concentration of $\mathrm{AB}$ ). The second peaks at $3.4 \AA$ are not due to a second coordination shell, but the non-bonding $\mathrm{H}_{\mathrm{B}} \mathrm{S}$ on the same $\mathrm{AB}$ molecule responsible for the $1.85 \AA$ peak.

The difference in the number of $\mathrm{AB}-\mathrm{AB}$ interactions between the two solvents can further be seen in an analysis of the $\mathrm{AB}-\mathrm{AB}$ clustering (a cluster defined as having an $\mathrm{H}_{\mathrm{N}} \cdots \mathrm{H}_{\mathrm{B}}$ distance of $2.7 \AA$ or less) present in the solutions, shown in Fig. 6. Overall $86 \%$ of the $\mathrm{AB}$ molecules in THF were in a cluster of size two or

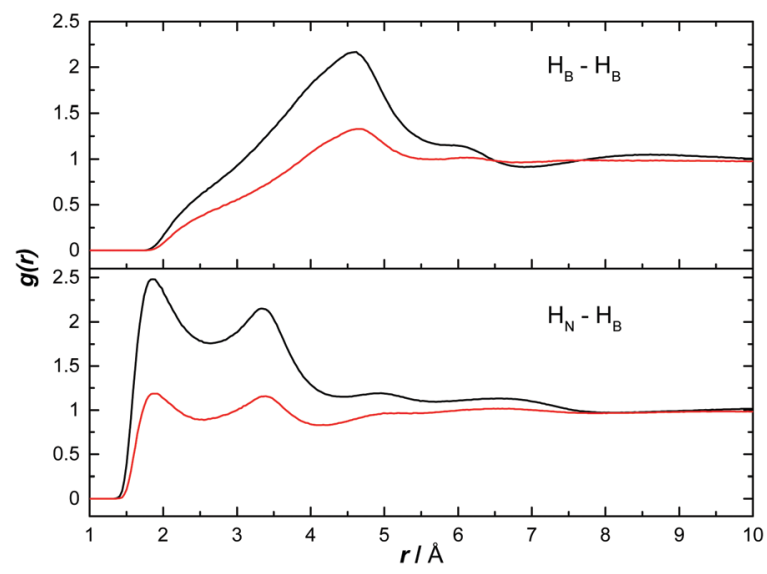

Fig. 5 Partial radial distribution functions for $A B-A B$ correlations via heteropolar $\mathrm{H}_{N} \cdots \mathrm{H}_{B}$ and homopolar $\mathrm{H}_{B} \cdots \mathrm{H}_{B}$ interactions. The red line corresponds to the EPSR simulation of $A B$ dissolved in ammonia and the black line that of $A B$ dissolved in THF. 


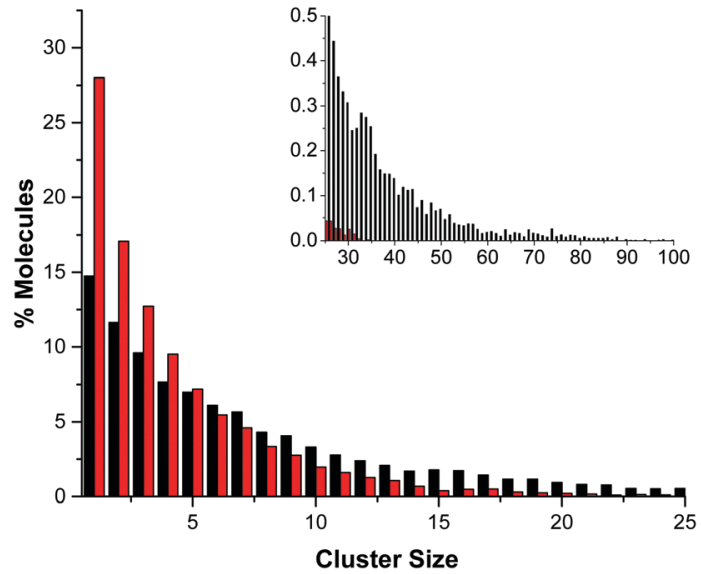

Fig. 6 Cluster size distribution for $A B-A B$ clusters in THF (black) and liquid ammonia (red). Clusters were defined as having an $\mathrm{H}_{N} \cdots \mathrm{H}_{B}$ distance of less than or equal to $2.7 \AA$, showing that long-range $A B-A B$ interactions are more common in THF than ammonia. The inset shows the much larger range in cluster size present in THF.

more, compared to $72 \%$ in liquid ammonia. This lower overall clustering in ammonia also manifested as a tendency towards smaller clusters, with the largest involving about $20 \mathrm{AB}$ molecules. In THF however, larger clusters were often observed containing over $30 \mathrm{AB}$ molecules. Each $\mathrm{H}_{\mathrm{N}}$ on average dihydrogen bonds to $0.701 \mathrm{H}_{\mathrm{B}} \mathrm{S}$ in THF, compared to only 0.438 in ammonia. This was determined from the average coordination numbers obtained by integrating the partial radial distribution functions. The results are shown in Table 2. More detailed probability distributions of the dihydrogen bonding in the first coordination shell $(<2.7 \AA)$ are shown in Fig. 7. These show that although the average coordination number is less than one, situations where multiple $\mathrm{H}_{\mathrm{N}} \mathrm{S}$ are dihydrogen bonded to each $\mathrm{H}_{\mathrm{B}}$ are not uncommon, more so in THF than in liquid ammonia, reflecting the increased clustering.

The lower clustering in ammonia suggests that $\mathrm{AB}-\mathrm{ammonia}$ interactions are relatively favourable compared to AB-THF. This may be linked to the ability of ammonia to partially break down the polymeric structure of the waste material, redistributing the residual $\mathrm{B}-\mathrm{H}$ bonds to form $\mathrm{AB}$ as mentioned before. ${ }^{18}$ This is a process that would be promoted by stronger $\mathrm{AB}$-solvent interactions, and is not observed in THF.

In Fig. 5, the peak signifying homopolar $\mathrm{H}_{\mathrm{B}} \cdots \mathrm{H}_{\mathrm{B}}$ interactions does not appear until $4.5 \AA$ A. This long range suggests that there

Table 2 First coordination shell numbers for $A B-A B$ interactions, as well as for $A B$-solvent interactions, for EPSR derived systems of $A B$ dissolved in THF and liquid ammonia. Coordination distances were defined by the location of the first minimum in the partial radial distribution functions

\begin{tabular}{lll}
\hline Atom pair & Range/A & Average coordination number \\
\hline $\mathrm{H}_{\mathrm{N}} \cdots \mathrm{H}_{\mathrm{B}}$ & 2.7 & $0.701(\mathrm{AB}-\mathrm{THF})$ \\
$\mathrm{H}_{\mathrm{N}} \cdots \mathrm{H}_{\mathrm{B}}$ & 2.7 & $0.438\left(\mathrm{AB}-\mathrm{NH}_{3}\right)$ \\
$\mathrm{H}_{\mathrm{N}} \cdots \mathrm{O} 1$ & 2.7 & 0.361 \\
$\mathrm{O} 1 \cdots \mathrm{H}_{\mathrm{N}}$ & 2.7 & 0.282 \\
$\mathrm{H}_{\mathrm{N}} \cdots \mathrm{N}_{\mathrm{A}}$ & 2.7 & 0.798 \\
$\mathrm{~N}_{\mathrm{A}} \cdots \mathrm{H}_{\mathrm{N}}$ & 2.7 & 0.258 \\
$\mathrm{H}_{\mathrm{B}} \cdots \mathrm{H}_{\mathrm{A}}$ & 2.5 & 1.905 \\
$\mathrm{H}_{\mathrm{A}} \cdots \mathrm{H}_{\mathrm{B}}$ & 2.5 & 0.206
\end{tabular}
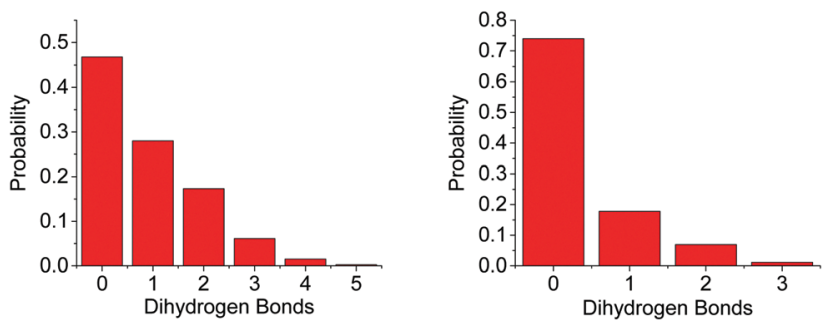

Fig. 7 Probability distributions of the number of $\mathrm{H}_{N} \mathrm{~S}$ in dihydrogen bonding distance $(<2.7 \AA)$ to an $\mathrm{H}_{\mathrm{B}}$, in the models of $\mathrm{AB}$ dissolved in THF (left) and liquid ammonia (right). These again highlight the greater $A B-A B$ interaction in THF.

are no direct correlations in these solutions. The density observed in these functions at this distance is likely instead due to the heteropolar interactions. This suggests that the presence of $\mathrm{D}_{2}$ during the dehydrogenation of $\mathrm{NH}_{3} \mathrm{BD}_{3}$, as observed by Wolstenholme et al., was more likely to be a result of hydrogen scrambling than homopolar coordination. ${ }^{12}$

Fig. 8 shows the spatial density functions (SDF) showing where neighbouring $\mathrm{AB}$ molecule density is located around a central $\mathrm{AB}$ in ammonia (similar SDFs are seen in THF). The density is broadly located side-on to the central $\mathrm{AB}$ rather than end-on, and adopts the three-fold symmetry expected for intermolecular interactions primarily based on the hydrogen bonding sites. Fig. 9 shows the angular $\mathrm{RDF}$ for the $\mathrm{AB}-\mathrm{AB}$ interactions, with $\theta$ corresponding to the angle between the $\mathrm{AB}$ dipole moments. The distance $r$ is that between $\mathrm{H}_{\mathrm{N}}$ and an $H_{B}$. The function shown is for $A B$ dissolved in THF, the same function calculated in liquid ammonia (Fig. S3, ESI $\dagger$ ) showed the same features. This implies that the only difference caused by the solvent is in the number of $\mathrm{AB}-\mathrm{AB}$ interactions rather than the structure. A strong bias towards anti-parallel dipole moments is observed. The side-on configuration shown in Fig. 9 is the only configuration where (heteropolar) dihydrogen bonding and anti-parallel dipole moments can occur together. The second peak, at $3.5 \AA$, is assigned to the distance between $\mathrm{H}_{\mathrm{N}}$ and the other $\mathrm{H}_{\mathrm{B}} \mathrm{S}$ on the dihydrogen bonding $\mathrm{AB}$.
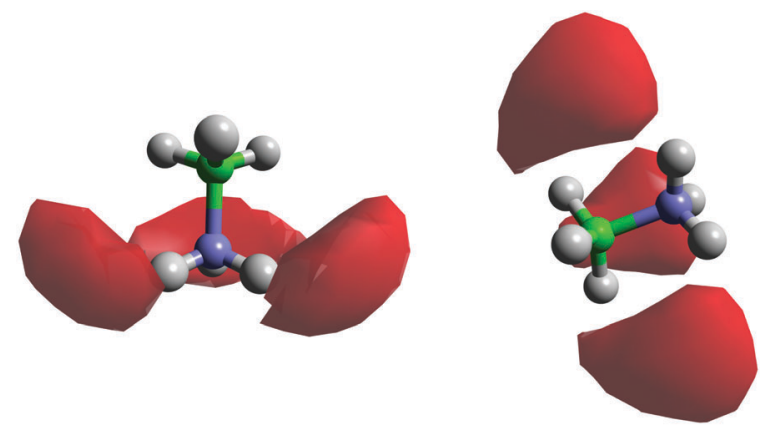

Fig. 8 Spatial density functions for $A B-A B$ interactions via $\mathrm{H}_{N} \cdots H_{B}$ dihydrogen bonds, for $A B$ dissolved in liquid ammonia. The density shows the $20 \%$ most likely positions for the neighbouring molecule's (left) $\mathrm{H}_{B} \mathrm{~S}$ and (right) $\mathrm{H}_{N} \mathrm{~s}$ in the first coordination shell, defined as having a distance of 2.0-4.0 $\AA$ between the centre of the three-fold symmetric hydrogens and the neighbouring molecule's heteropolar hydrogen. The blue atom is the AB nitrogen and the green the boron. 

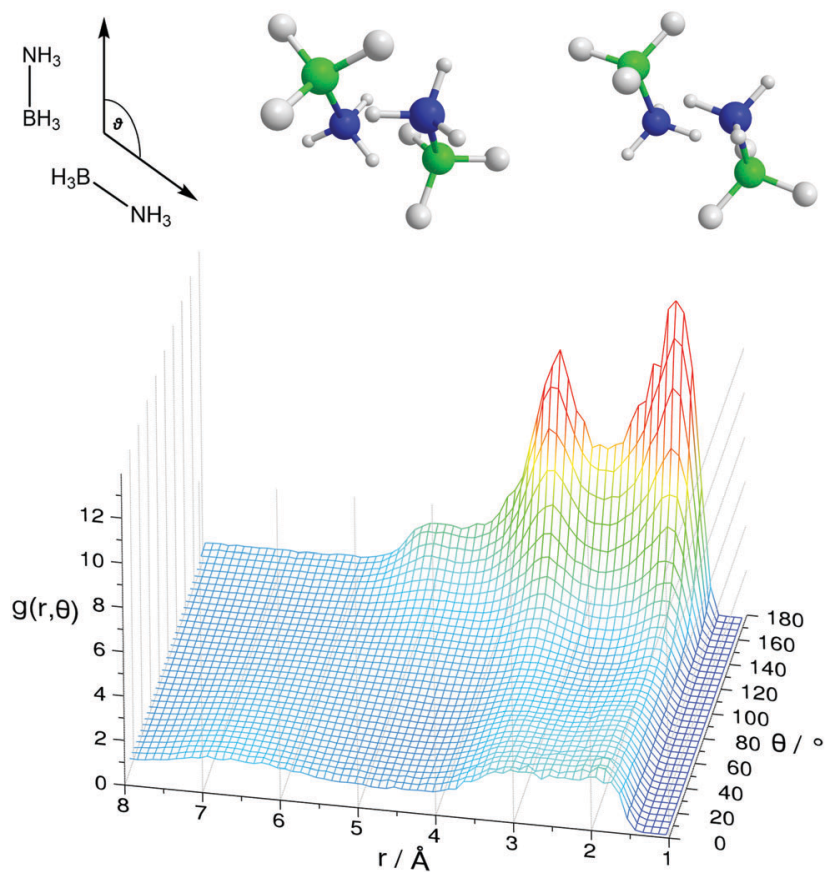

Fig. 9 Angular radial distribution function for $A B-A B$ pairs in $T H F$, showing the anti-parallel nature of the $A B$ dipoles. The angle $\theta$ is defined above, along with $A B-A B$ orientations that satisfies the graph as well as the spatial density functions. The distance is that between $\mathrm{H}_{N}$ and an $\mathrm{H}_{B}$. The blue atom is the $A B$ nitrogen and green the $A B$ boron.

In the angular RDF in Fig. S4 (ESI $\dagger$ ) with $\theta$ equal to the angle between the $\mathrm{N}-\mathrm{H}$ bonds, a preference for both a parallel and anti-parallel orientation of the $\mathrm{N}-\mathrm{H}$ bonds is seen. The resulting $\mathrm{AB}-\mathrm{AB}$ pairs fulfilling all of the above criteria are shown in Fig. 9. The $\mathrm{N}-\mathrm{H}_{\mathrm{N}}$ bonds point towards the $\mathrm{B}-\mathrm{H}_{\mathrm{B}}$ bonds, rather than directly at the $\mathrm{H}_{\mathrm{B}} \mathrm{S}$. This structure, observed before in theoretical studies of dimers, has been suggested to be favourable by allowing the protonic hydrogen to get nearer to the relatively negative boron atom. ${ }^{41}$ As a result, it was proposed that the $\sigma$-bond itself was the acceptor in the dihydrogen bond rather than just the hydridic hydrogen. ${ }^{20}$ This may also explain how multiple dihydrogen bonds can form with a particular $\mathrm{H}_{\mathrm{B}}$, as $\mathrm{H}_{\mathrm{N}} \mathrm{S}$ can bond from many angles surrounding the $\sigma$ bond rather than from only pointing directly at the $\mathrm{H}_{\mathrm{B}}$ (regular hydrogen bonds typically being linear, see Section 2.4).

In considering the $\mathrm{H}_{\mathrm{N}}$ density in Fig. 8 near to the nitrogen end of $A B$, we note that there is no close-range $\mathrm{H}_{\mathrm{N}} \cdots \mathrm{H}_{\mathrm{N}}$ homopolar correlation either, the peak in the partial RDF appearing at approximately $4.2 \AA$ (Fig. S6, ESI $\dagger$ ).

\subsection{Ammonia borane-tetrahydrofuran interactions}

The $\mathrm{H}$ to $\mathrm{O}$ partial RDFs for $\mathrm{AB}$ dissolved in THF are shown in Fig. 10. Only $\mathrm{H}_{\mathrm{N}}$ shows strong interactions to $\mathrm{O} 1$ with two contacts at 2.05 and $3.44 \AA$ respectively. The first is attributed to a direct $\mathrm{H}_{\mathrm{N}} \cdots \mathrm{O} 1$ hydrogen bond while the second peak is due to a longer range interaction between the oxygen and another $\mathrm{H}_{\mathrm{N}}$ on the same nitrogen. As expected, given the hydridic nature of $\mathrm{H}_{\mathrm{B}}$, the $\mathrm{H}_{\mathrm{B}} \cdots \mathrm{O} 1 \mathrm{RDF}$ shows only a much longer range interaction, indicated by a broad peak centred at $4.83 \AA$.

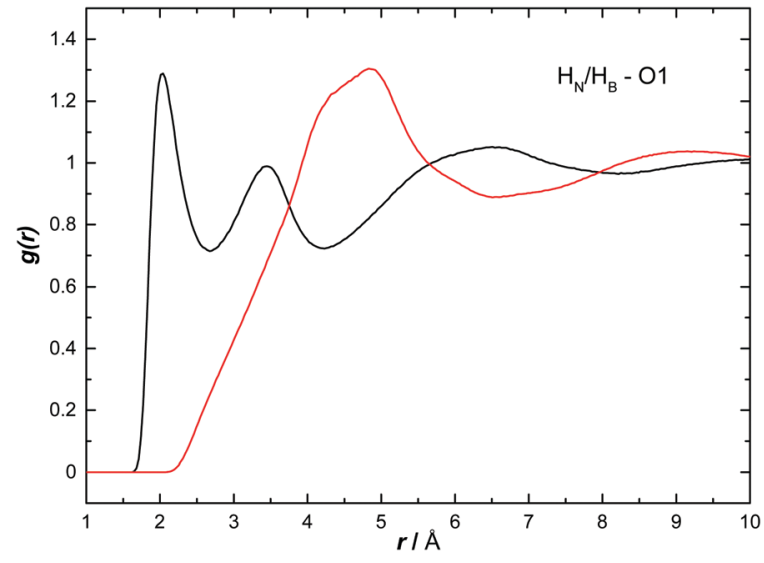

Fig. 10 Partial radial distribution functions for $\mathrm{H}_{N}$ (black) and $\mathrm{H}_{B}$ (red) to O1, calculated from the EPSR fitted system, for AB dissolved in THF.
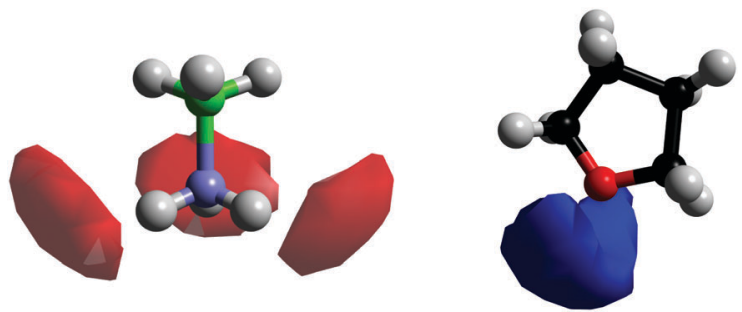

Fig. 11 Spatial density functions showing the location of the $20 \%$ most likely positions for molecules in the first coordination shell (2.0-3.6 $\AA$ ) around $A B$ and THF. The red density is the position of the THF O1s and the blue density the $A B H_{N}$. The blue $A B$ atom is the $A B$ nitrogen.

Fig. 11 shows the SDFs plotting the regions of highest probability density around the $\mathrm{AB}$ and THF in which the other molecule is located. These show that the density is centred around the hydrogen bonding sites $\mathrm{O} 1$ and $\mathrm{H}_{\mathrm{N}}$. Fig. 12 shows the angular $\mathrm{RDF}$, where the angle $\theta$ is that between the $\mathrm{AB}$ and THF dipoles, and the distance $r$ is that between $\mathrm{H}_{\mathrm{N}}$ and O1. A roughly equal, high probability is seen for orientations with $\theta$ between 90 and $180^{\circ}$. Together with the SDFs and other angular RDFs (Fig. S7-S9, $\mathrm{ESI} \dagger$ ), we can determine that THF occupies a range around the nitrogen end of $\mathrm{AB}$, with $\mathrm{O} 1$ always pointing at $\mathrm{H}_{\mathrm{N}}$. This can involve a disruption of the usual tendency for pairs to align with anti-parallel dipole moments, which speaks to the strength of the hydrogen bonding interactions. It could also be a result of the increased degree of disorder present in liquid samples.

On average, each $\mathrm{H}_{\mathrm{N}}$ coordinates to $0.361 \mathrm{O} 1 \mathrm{~s}$, suggesting it is about twice as likely for an $\mathrm{AB}\left(\right.$ via $\left.\mathrm{H}_{\mathrm{N}}\right)$ to bond to another $\mathrm{AB}$ (0.701) than to a THF molecule. A more detailed distribution of the AB-THF coordination is shown in Fig. 13, which also shows that it is much less likely for each $\mathrm{H}_{\mathrm{N}}$ to be within hydrogen bonding distance of more than one $\mathrm{O} 1$, than with multiple $\mathrm{H}_{\mathrm{B}} \mathrm{S}$ (Fig. 7). Looking at the distribution of $\mathrm{H}_{\mathrm{N}} \mathrm{S}$ around $\mathrm{O} 1 \mathrm{~s}$ also reveals that the THF oxygen can be within hydrogen bonding range of two $\mathrm{H}_{\mathrm{N}} \mathrm{S}$ at once, suggesting that both of the oxygen non-bonding electron pairs could be involved in hydrogen bonding at the same time. 

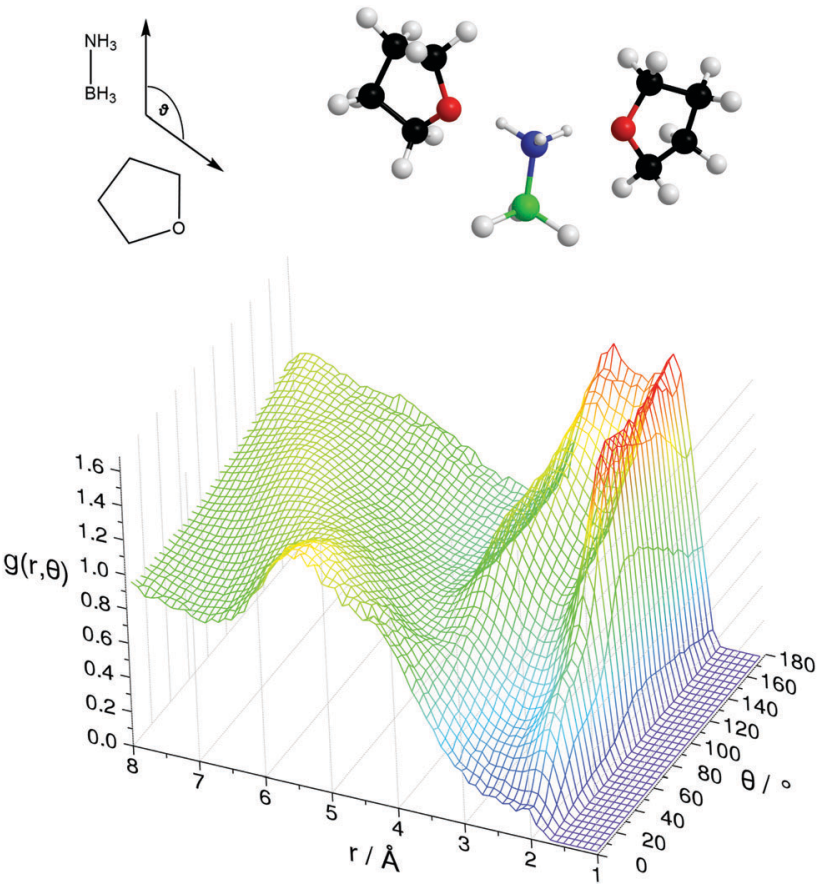

Fig. 12 Angular radial distribution function for AB-THF interactions, illustrating the hydrogen bonding between $\mathrm{H}_{N}$ and $\mathrm{O} 1 . \theta$ is the angle between the $A B$ and THF dipole moments. The distance is calculated between $H_{N}$ and $\mathrm{O} 1 . \mathrm{AB}-\mathrm{THF}$ orientations that fit these peaks and the spatial density functions are shown above.
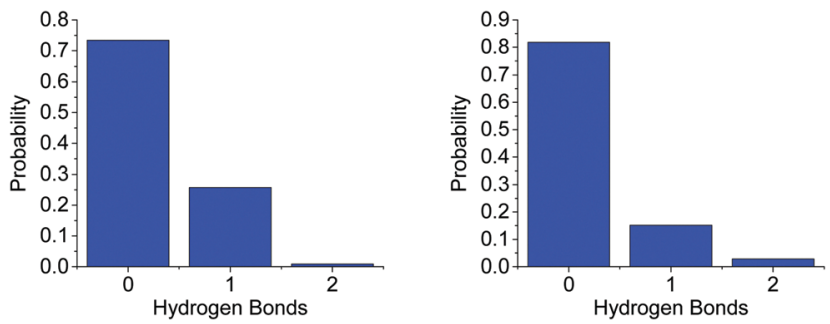

Fig. 13 Probability distribution of (left) the number of O1s in hydrogen bonding distance $(<2.7 \AA)$ to each $\mathrm{H}_{N}$ and (right) the number of $\mathrm{H}_{N} \mathrm{~S}$ around $\mathrm{O} 1$, for the model of $\mathrm{AB}$ dissolved in THF.

\subsection{Ammonia borane-ammonia interactions}

Fig. 14 shows the $\mathrm{AB} H$ to ammonia $\mathrm{N}_{\mathrm{A}}$ and $\mathrm{H}_{\mathrm{A}}$ partial RDFs. $\mathrm{H}_{\mathrm{A}}$ predominantly interacts with $\mathrm{H}_{\mathrm{B}}$, as can be seen by the defined peak at $1.98 \AA$. This is a slightly longer dihydrogen bond than the corresponding bond between two ABs $\left(\mathrm{H}_{\mathrm{N}} \cdots \mathrm{H}_{\mathrm{B}}, 1.9 \AA\right)$, suggesting it may be weaker. $\mathrm{H}_{\mathrm{N}}$, however, does not seem to dihydrogen bond directly with $\mathrm{H}_{\mathrm{A}}$, the 'shoulder' peak at $2.7 \AA$ instead likely due to $\mathrm{AB}$ bonded via the $\mathrm{H}_{\mathrm{B}}$, as was observed in Ricci et $a .^{42}$ The opposite was determined for bonding to $\mathrm{N}_{\mathrm{A}}$, with $\mathrm{H}_{\mathrm{N}}$ showing a clear peak at 2.19 $\AA$. $\mathrm{H}_{\mathrm{B}}$ however does not show any bonding to $\mathrm{N}_{\mathrm{A}}$ before the first peak at $2.88 \AA$, likely again caused by bonding to the other end of $\mathrm{AB}$. The extra dihydrogen bonding interactions observed between $A B$ and ammonia, and not present in THF, are likely responsible for the large difference in solubilities.

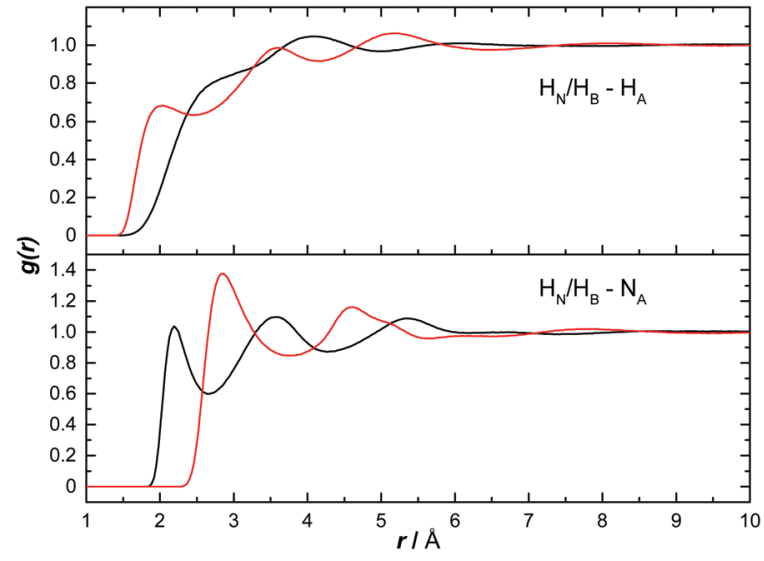

Fig. 14 Partial radial distribution functions for $\mathrm{H}_{N}$ (black) and $\mathrm{H}_{B}$ (red) to $H_{A}$ as well as to $N_{A}$, calculated from the EPSR fitted system, for $A B$ dissolved in liquid ammonia.
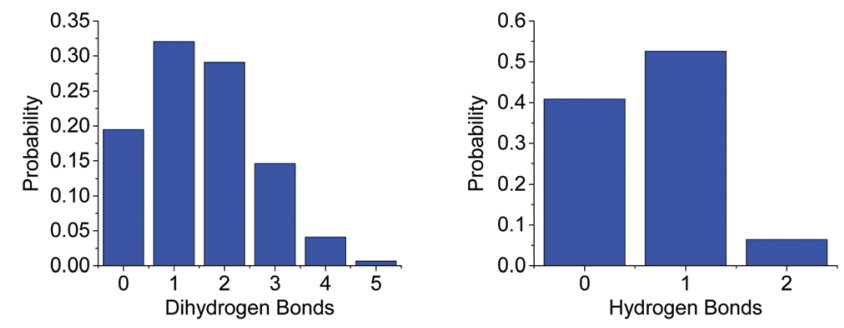

Fig. 15 Probability distributions of the number of (left) $\mathrm{H}_{A} \mathrm{~S}$ within dihydrogen bonding range $(<2.5 \AA)$ of $\mathrm{H}_{B} \mathrm{~S}$ and (right) the number of $\mathrm{N}_{A} \mathrm{~S}$ in the same distance of $\mathrm{H}_{\mathrm{N}}$, for $\mathrm{AB}$ dissolved in liquid ammonia.

The average first shell $(<2.5 \AA)$ coordination number of $\mathrm{N}_{\mathrm{A}}$ around $\mathrm{H}_{\mathrm{N}}$, and of $\mathrm{H}_{\mathrm{A}}$ around $\mathrm{H}_{\mathrm{B}}$ is 0.798 , and 1.905 respectively. The latter is remarkably high, possibly due to the large number of $\mathrm{H}_{\mathrm{A}} \mathrm{S}$ in the system compared to $\mathrm{N}_{\mathrm{A}} \mathrm{S}$. Something of note though in comparing to THF, is the effective doubling of the average coordination number of $\mathrm{O} 1$ around $\mathrm{H}_{\mathrm{N}}(0.361)$ in regards to $\mathrm{N}_{\mathrm{A}}$. While it is likely this is at least partly due to the higher concentration of $\mathrm{AB}$ in ammonia, the smaller size of the ammonia molecule may also make it less sterically unfavourable for multiple $\mathrm{H}_{\mathrm{N}} \mathrm{S}$ on an $\mathrm{AB}$ to be coordinated. Fig. 15 shows the more detailed analysis of the coordination, which reveals just how frequently $\mathrm{H}_{\mathrm{B}} \cdots \mathrm{H}_{\mathrm{A}}$ dihydrogen bonds occur. As many as five $\mathrm{H}_{\mathrm{A}} \mathrm{S}$ were observed to be within dihydrogen bonding distance of one $\mathrm{H}_{\mathrm{B}}$, eclipsing the coordination observed in THF. The coordination is also weighted more towards one or two bonds rather than zero as was observed in the $\mathrm{AB}-\mathrm{AB}$ coordination in THF.

The SDFs for AB-ammonia pairs are shown in Fig. 16. The density around $\mathrm{AB}$ largely mirrors that seen in the previous pairs, a three-fold symmetrical pattern of density around the $\mathrm{H}_{\mathrm{N}} \mathrm{S}$, and between the $\mathrm{H}_{\mathrm{B}} \mathrm{S}$. In this case, the lobes of density between the $\mathrm{H}_{\mathrm{B}} \mathrm{S}$ also extend down to meet end-on to the boron atom, unlike in the $\mathrm{AB}-\mathrm{AB}$ pair. This could reflect the extreme prevalence of $\mathrm{H}_{\mathrm{B}} \cdots \mathrm{H}_{\mathrm{A}}$ dihydrogen bonds, and the smaller size of the ammonia molecule relative to $\mathrm{AB}$ enabling it to bond from positions where the larger $\mathrm{AB}$ could not. This large volume 

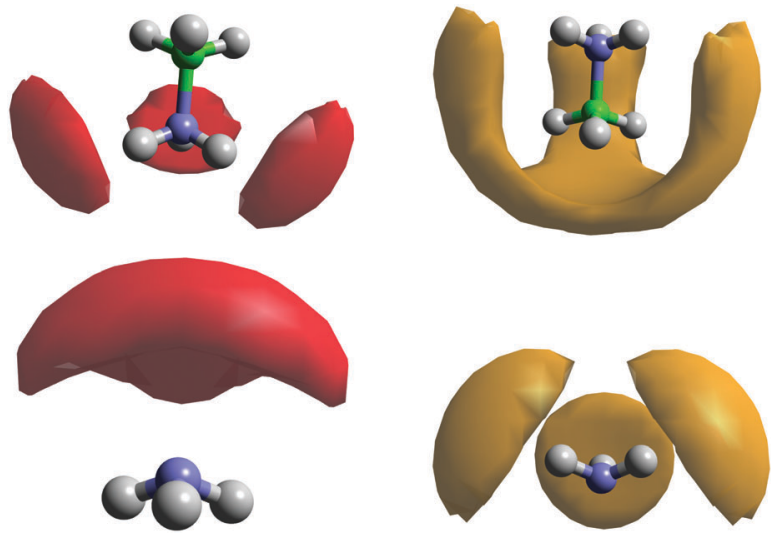

Fig. 16 Spatial density functions showing the location of the $20 \%$ most likely positions for ammonia or $\mathrm{AB}$ molecules in the first coordination shell around the other, for the model solution of $A B(20 w t \%)$ in ammonia. The red density shows the $H_{N}$ to $N_{A}$ pair in a range of 2.2-3.5 $\AA$, while the orange density shows the $H_{B}$ to $H_{A}$ pair in a range of $2.2-4.2 \AA$.
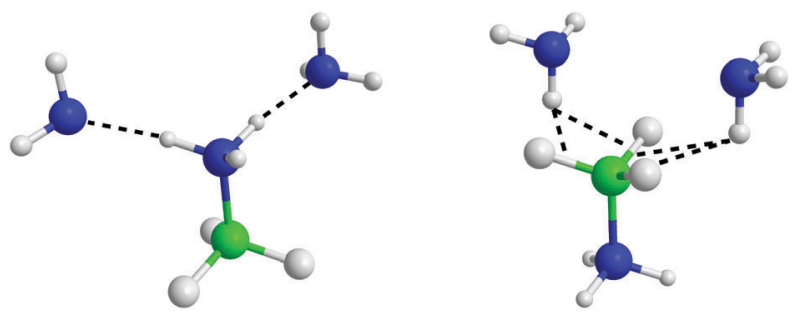

Fig. $17 \mathrm{AB}$-ammonia orientations that satisfy the spatial density functions and angular radial distribution functions.

of probability density may also be the reason that a coordination number as high as 5 can be observed, albeit very rarely. The location of the probability density being between the $\mathrm{H}_{\mathrm{B}} \mathrm{S}$ rather than pointing at them again highlights that it is the $\mathrm{B}-\mathrm{H}_{\mathrm{B}} \sigma$ bond that is acting as the dihydrogen bond acceptor.

The angular RDFs were split into those calculated based on $\mathrm{H}_{\mathrm{N}} \cdots \mathrm{N}_{\mathrm{A}}$, and $\mathrm{H}_{\mathrm{B}} \cdots \mathrm{H}_{\mathrm{A}}$ interactions. These are shown in Fig. S10 and $\mathrm{S} 11$ (ESI $\dagger$ ) respectively. Orientations that satisfy the ARDFs and the SDFs, are shown in Fig. 17. The additional angular RDFs needed to narrow down the most probable orientations are shown in Fig. S12 and S13 (ESI $\dagger$ ).

\subsection{Directionality of dihydrogen bonding in solution}

The hydrogen and dihydrogen bonding angles $\mathrm{X}-\mathrm{H} \cdots \mathrm{Y}$ observed throughout the simulations, where $\mathrm{X}$ is the hydrogen bond donor and $\mathrm{Y}$ the acceptor, were determined with the resulting probability distributions shown in Fig. 18. All the interactions are predominantly linear, matching what would be expected for hydrogen bonds. ${ }^{1}$ The dihydrogen bonds however, show wider peaks than the regular hydrogen bonds, indicating more flexibility. This could reflect a slightly weaker bond, or be a product of the larger number of these interactions forcing some to adopt a less ideal orientation. The other angles $\mathrm{XH} \cdots \mathrm{Y}-\mathrm{A}$, where $\mathrm{A}$ is an atom covalently bound to $\mathrm{Y}$, were also determined and shown in Fig. 19. The peaks are much wider for these angles, reflecting less rigidity. The $\mathrm{H}_{\mathrm{N}} \cdots \mathrm{H}_{\mathrm{B}}-\mathrm{B}$

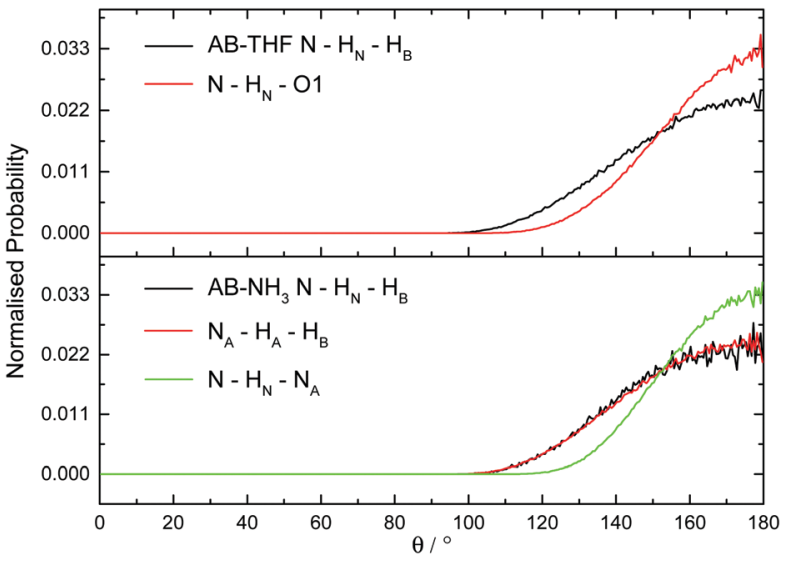

Fig. 18 Normalised probability distributions for the angle $\mathrm{X}-\mathrm{H} \ldots Y$, where $X$ is the hydrogen bond donor and $Y$ the acceptor, in (top) $A B$ dissolved in THF and (bottom) AB dissolved in liquid ammonia.

angle however predominantly appears at $90^{\circ}$. This is due to the dihydrogen bond acceptor formally being the $\mathrm{H}_{B}-\mathrm{B} \sigma$ bond rather than just the hydridic hydrogen, as was seen in the SDF (Fig. 8). For the $\mathrm{H}_{\mathrm{A}} \cdots \mathrm{H}_{\mathrm{B}}-\mathrm{B}$ dihydrogen bond, a slightly larger angle of $110^{\circ}$ is seen. This may be due to $\mathrm{H}_{\mathrm{N}}$ having a slightly more positive charge than $\mathrm{H}_{\mathrm{A}}$, and therefore experiencing a stronger attraction to the electron density in the $\sigma$ bond.

Analysing the angles of the (di)hydrogen bonds also enables us to distinguish these from other intermolecular interactions (such as van der Waals forces). Fig. S14 (ESI $\dagger$ ) shows the angular distribution for the non-(di)hydrogen bonding $\mathrm{B}-\mathrm{H}_{\mathrm{B}} \cdots \mathrm{H}_{\mathrm{B}}$. The distribution is very flat, with the reduction in probability at $<120^{\circ}$ likely due to steric reasons. This is very different to what we see in the (di)hydrogen bonds, which all seem to show directionality.

\subsection{Comparison of ammonia borane-ammonia results to a theoretical approach}

After observing that (di)hydrogen bonding to both ends of the $\mathrm{AB}$ molecule by ammonia was occurring, the possibility was raised that a single ammonia could bond to both ends of the

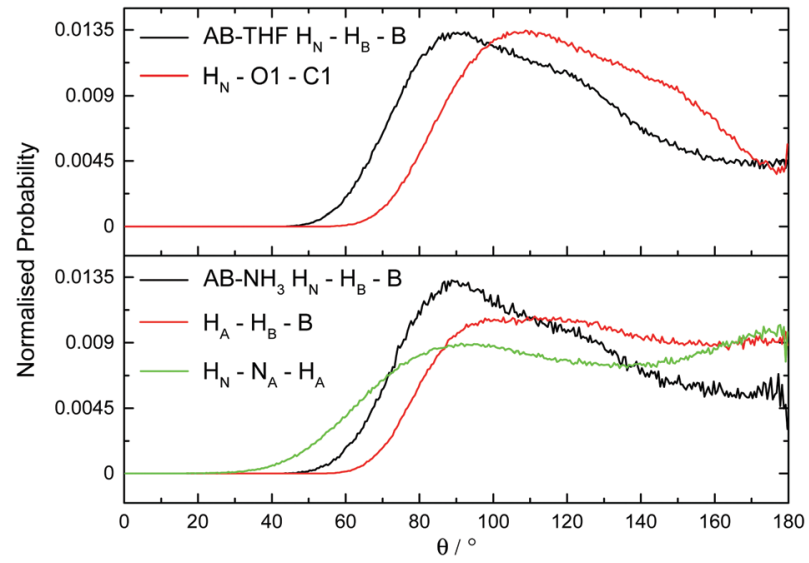

Fig. 19 Normalized probability distributions for the angle $A-Y$...HX, where $Y$ is the hydrogen bond acceptor and $X$ the donor, in (top) $A B$ dissolved in THF and (bottom) AB dissolved in liquid ammonia. 


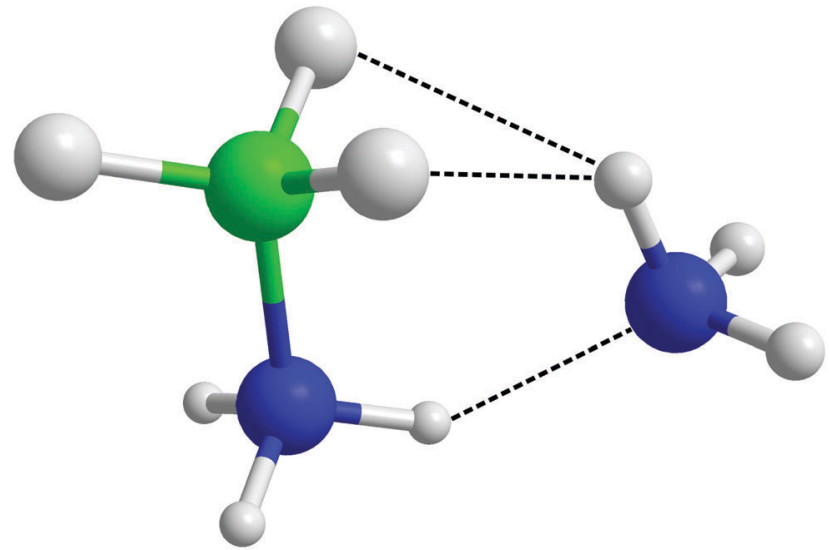

Fig. 20 Theoretically optimised $A B$-ammonia dimer in which bonding to both sides of the $A B$ molecule from one ammonia is observed. ${ }^{43}$

same $\mathrm{AB}$. Indeed in theoretical studies run on systems of $\mathrm{AB}$ dissolved in ammonia by Kar and Scheiner, their fully relaxed AB- $\mathrm{NH}_{3}$ dimer (Fig. 20) showed $\mathrm{H}_{\mathrm{N}} \cdots \mathrm{N}_{\mathrm{A}}$ hydrogen bonding as well as $\mathrm{H}_{\mathrm{A}}$ dihydrogen bonding to two $\mathrm{H}_{\mathrm{B}} \mathrm{S} .{ }^{43}$ Looking for pairs where (di)hydrogen bonding occurs on both ends of an $\mathrm{AB}$ molecule to one $\mathrm{NH}_{3}$ in our empirically refined simulation showed that this occurred $32 \%$ of the time (out of all bonding pairs). Dihydrogen bonding was determined by the atom pairs satisfying distance constraints of $<2.7 \AA$ for $\mathrm{H}_{\mathrm{N}} \cdots \mathrm{N}_{\mathrm{A}}$ and $<2.5 \AA$ for $\mathrm{H}_{\mathrm{B}} \cdots \mathrm{H}_{\mathrm{A}}$. These constraints were chosen to include the full breadth of the corresponding peak in the partial RDFs. Angular constraints were not included as any orientation which involves bonding to both sides of the $\mathrm{AB}$ would be radically different to what we saw in the prior analysis. Searching specifically for the bonding pattern in the theoretically optimised dimer (one $\mathrm{H}_{\mathrm{A}}$ dihydrogen bonding to two $\mathrm{H}_{\mathrm{B}} \mathrm{S}$, and $\mathrm{N}_{\mathrm{A}}$ hydrogen bonding to one $\mathrm{H}_{\mathrm{N}}$ ), showed it as present only $4.2 \%$ of the time. The average geometric parameters were also quite different $\left(\mathrm{H}_{\mathrm{N}} \cdots \mathrm{N}_{\mathrm{A}}\right.$ lit. $1.993 \AA$, exp. $2.455 \AA ; \mathrm{H}_{\mathrm{A}} \cdots \mathrm{H}_{\mathrm{B}}$ lit. $2.495 \AA$, exp. $2.155 \AA$; $\mathrm{N}-\mathrm{H}_{\mathrm{N}} \cdots \mathrm{N}_{\mathrm{A}}$ lit. $150.4^{\circ}$, exp. $130.3^{\circ} ; \mathrm{H}_{\mathrm{A}} \cdots \mathrm{H}_{\mathrm{B}}-\mathrm{B}$ lit. $88.6^{\circ}$, exp. $\left.86.9^{\circ}\right) .{ }^{43}$ The closest match was the last angle, which the authors claimed to show energy minima at 100 and $180^{\circ}$; in this work we see broad corresponding probability peaks at about 90 and $180^{\circ}$ (Fig. 19). The broadness of the peaks and the relatively small differences between experimental and theoretical results reflects the disordered nature of the liquid samples. The theoretical model also only had to minimise the energy of two molecules, while in the liquid multiple interactions had to be globally minimised. The chelate effect would suggest that solvation structures where one ammonia bonds to both ends of $\mathrm{AB}$ would be favoured, considering the increase in entropy gained from displacing other ammonia molecules. Nevertheless the probabilities were quite low, this may be because such orientations diverge from the most favourable angles (Fig. S10 and S11, ESI $\dagger$ ); the multiply bonded pairs have $\mathrm{H}_{\mathrm{A}}-\mathrm{N}_{\mathrm{A}}$ running parallel to the $\mathrm{AB}$ dipole rather than anti-parallel.

\section{Conclusions}

The solvation structure of $\mathrm{AB}$ by $\mathrm{THF}$ and liquid ammonia has been determined via refinement of a Monte Carlo simulation to neutron diffraction data, constrained by complementary data sets of isotopically substituted samples. The large capacity of $\mathrm{AB}$ to hydrogen bond was found to dominate the solute-solvent interactions. In THF, hydrogen bonding via the oxygen was usually observed to happen only once per THF, with instances where both non-bonding electron pairs were involved occurring five times less frequently. The low number of hydrogen bonds formed with $\mathrm{THF}$, along with the larger and more rigid size relative to another $\mathrm{AB}$, caused $\mathrm{AB}-\mathrm{AB}$ contacts to be favoured over $\mathrm{AB}-\mathrm{THF}$. This manifested as a noticeable increase in $\mathrm{AB}$ clustering.

The extreme solubility of $\mathrm{AB}$ in liquid ammonia could then be seen in the sheer number of (di)hydrogen bonds formed on average between $\mathrm{AB}$ and ammonia. The first shell coordination number of $\mathrm{N}_{\mathrm{A}}$ around $\mathrm{H}_{\mathrm{N}}$ was more than double that of the THF oxygen around $\mathrm{H}_{\mathrm{N}}$. This could be due to the increased availability of the nitrogen lone pair compared to the oxygen non-bonding electron pairs. The $\mathrm{H}_{\mathrm{B}} \cdots \mathrm{H}_{\mathrm{A}}$ dihydrogen bond in particular was prevalent, with a coordination number roughly 2.5 times greater than even $\mathrm{N}_{\mathrm{A}}$ around $\mathrm{H}_{\mathrm{N}}$. This also came with a relative decrease in $\mathrm{AB}$ clustering.

The structure of the dihydrogen bonding between $\mathrm{AB}$ and either ammonia or another $\mathrm{AB}$ in solution was determined to be very directional, with the $\mathrm{N}-\mathrm{H}_{\mathrm{N} / \mathrm{A}} \cdots \mathrm{H}_{\mathrm{B}}$ angle centred around $180^{\circ}$. This was still slightly less rigid than regular hydrogen bonds. The frequency of these interactions was attributed to the preference for a $90^{\circ} \mathrm{H}_{\mathrm{N} / \mathrm{A}} \cdots \mathrm{H}_{\mathrm{B}}-\mathrm{B}$ angle, which enabled the bonding to occur from a much larger volume of space surrounding each $\mathrm{H}_{\mathrm{B}}$. This may also be the reason for the lower rigidity of $\mathrm{N}-\mathrm{H}_{\mathrm{N} / \mathrm{A}} \cdots \mathrm{H}_{\mathrm{B}}$, as some distortion of the linearity to point towards the $\mathrm{B}-\mathrm{H}_{\mathrm{B}}$ $\sigma$ bond would be expected.

The fact that ammonia can hydrogen bond to both ends of the $\mathrm{AB}$ molecule undoubtedly leads to an increased solubility of $\mathrm{AB}$ compared to in THF. In comparing to $\mathrm{AB}-\mathrm{AB}$ contacts however, which can also occur on both ends of the molecule, $\mathrm{AB}-$ ammonia contacts were still preferred. We determined this could be due to the smaller size of the ammonia molecule opening up new volumes of space in which hydrogen bonding could occur from. This was mainly observed in an end-on position next to the $\mathrm{AB}$ boron.

It is the combination of these factors that cause the high solubility of $\mathrm{AB}$ in liquid ammonia. An interesting test would be to study in a similar way the solvation structure of $\mathrm{AB}$ in water, as water also has a small size and could bond to both ends of $\mathrm{AB}$. The solubility in water (33.6 $\mathrm{g}$ AB per $100 \mathrm{~g}$ solvent) however is more similar to that in THF (25 g AB) than ammonia $(260 \mathrm{~g} \mathrm{AB}) .{ }^{11}$ This could perhaps place more weight on the availability of the lone pair as well as the number of hydrogens involved in terms of factors contributing to solubility. It could also be possible that the three-fold symmetry of the ammonia is complementary to the $\mathrm{AB}$ symmetry, and enables a larger degree of dihydrogen bonding between the two.

In terms of implications towards $\mathrm{AB}$ regeneration, the sheer favourability in ammonia of the $\mathrm{H}_{\mathrm{B}} \cdots \mathrm{H}_{\mathrm{A}}$ dihydrogen bonds may be the reason for the observed $\mathrm{B}-\mathrm{H}$ bond redistribution in $\mathrm{AB}$ waste treated with ammonia. ${ }^{18}$ Typically, the reduction of 
$\mathrm{BX}_{3}(\mathrm{X}=\mathrm{O}, \mathrm{S}$, or halide $)$ to $\mathrm{BH}_{3}$ is the highest energy step in regeneration. In ammonia however, the formation of $\mathrm{BH}_{3}$ would be stabilised by the numerous dihydrogen bonds formed with the $\mathrm{H}_{\mathrm{A}} \mathrm{s}$, making the reduction more facile. Ammonia can also stabilise the formation of $\mathrm{AB}$ via interacting with the other end of the molecule through a regular hydrogen bond. This is the only interaction possible in other coordinating solvents like THF and other ethers, which lack the multitude of partially positive hydrogens ammonia has and therefore cannot stabilise $\mathrm{BH}_{3}$. An example of a different solvent that does is water, but that raises issues in terms of incompatibility with reducing agents like sodium borohydride, that ammonia does not have. This explains the relative success of regeneration processes in ammonia, and suggests that any energetically efficient regeneration would be wise to use it as a solvent.

\section{Experimental}

${ }^{11} \mathrm{~B}$ enriched ammonia borane was synthesised following the procedure described in Ramachandran and Gagare. ${ }^{44}$ ${ }^{11} \mathrm{~B}$ enriched sodium borohydride and borodeuteride were sourced from Katchem, ammonium sulfate from Alfa Aesar, and the THF from Sigma-Aldrich. Deuteration of the nitrogen hydrogens was achieved by dissolving in $\mathrm{D}_{2} \mathrm{O}$ and removing the solvent under reduced pressure three times. All the chemicals were used as received without further purification. For the neutron scattering experiments, the THF and ammonia were both sourced from Sigma-Aldrich and again used without further purification.

The neutron scattering experiments were run on the Small Angle Neutron Diffractometer for Amorphous and Liquid Samples (SANDALS) beamline at the spallation neutron source ISIS, at the Rutherford Appleton Laboratory, Didcot, UK. ${ }^{45}$ The neutron diffraction patterns of $\mathrm{ND}_{3} \mathrm{BD}_{3}, \mathrm{NH}_{3} \mathrm{BH}_{3}$ and $\mathrm{ND}_{3} \mathrm{BH}_{3}$ were measured dissolved in $\mathrm{THF}$ and $\mathrm{THF}-\mathrm{d}_{8}$, as well as $\mathrm{ND}_{3} \mathrm{BD}_{3}$ in a mixture of 50:50 THF: THF- $\mathrm{d}_{8}$. The $\mathrm{ND}_{3} \mathrm{BD}_{3}$ in THF- $\mathrm{d}_{8}$ sample was $12 \mathrm{wt} \% \mathrm{AB}$, with the other samples in the same mole ratio. For the ammonia experiments, less combinations were possible due to exchanging of the ammonia protons with the $\mathrm{AB} \mathrm{N}-\mathrm{Hs}$. $\mathrm{ND}_{3} \mathrm{BD}_{3}$ and $\mathrm{ND}_{3} \mathrm{BH}_{3}$ were dissolved and measured in $\mathrm{ND}_{3}$ along with $\mathrm{NH}_{3} \mathrm{BD}_{3}$ in $\mathrm{NH}_{3}$. The $\mathrm{ND}_{3} \mathrm{BD}_{3}$ in $\mathrm{ND}_{3}$ sample was $20 \mathrm{wt} \% \mathrm{AB}$, with the other samples in the same mole ratio.

The samples in THF were prepared under an inert atmosphere before being sealed in a cell made of a null-scattering titanium/zirconium alloy. The cell had a flat-plate geometry facing the neutron beam to reduce multiple scattering and absorption. ${ }^{39}$ The diffraction pattern was measured at room temperature, monitored by a thermocouple, and the length of each experiment was approximately 8 hours. The samples in ammonia were measured in the same cell at $220 \mathrm{~K}$, with the ammonia being condensed directly into the cell. The data correction method followed was that implemented by the Gudrun program. ${ }^{46}$ This involved taking a background measurement of the empty instrument, the empty sample cell, and an incoherently scattering vanadium slab. Gudrun was also used to correct for the inelastic self-scattering using 'top-hat' deconvolution and an iterative method before the analysis by EPSR. ${ }^{40,47}$ Analysis of the final simulation box after EPSR was performed using the dlputils software. ${ }^{48}$

\section{Conflicts of interest}

There are no conflicts to declare.

\section{Acknowledgements}

The authors thank the EPSRC (EP/L504889/1) and Cella Energy for funding, as well as the ISIS Neutron Scattering Facility for beamtime allocations RB1610270 and RB1610293 on SANDALS. We also thank Prof. Alan Soper for assistance with the THF EPSR simulation.

\section{References}

1 E. Arunan, G. R. Desiraju, R. A. Klein, J. Sadlej, S. Scheiner, I. Alkorta, D. C. Clary, R. H. Crabtree, J. J. Dannenberg, P. Hobza, H. G. Kjaergaard, A. C. Legon, B. Mennucci and D. J. Nesbitt, Pure Appl. Chem., 2011, 83, 1619-1636.

2 N. V. Belkova, L. M. Epstein, O. A. Filippov and E. S. Shubina, Chem. Rev., 2016, 116, 8545-8587.

3 S. C. Gatling and J. E. Jackson, J. Am. Chem. Soc., 1999, 121, 8655-8656.

4 X. Chen, J.-C. Zhao and S. G. Shore, Acc. Chem. Res., 2013, 46, 2666-2675.

5 D. G. Allis, M. E. Kosmowski and B. S. Hudson, J. Am. Chem. Soc., 2004, 126, 7756-7757.

6 W. J. Shaw, M. Bowden, A. Karkamkar, C. J. Howard, D. J. Heldebrant, N. J. Hess, J. C. Linehan and T. Autrey, Energy Environ. Sci., 2010, 3, 796.

7 S. M. Kathmann, C. J. Mundy, G. K. Schenter, T. Autrey, P. C. Aeberhard, B. David, M. O. Jones and T. RamirezCuesta, J. Phys. Chem. C, 2012, 116, 5926-5931.

8 K. M. Dreux, L. E. McNamara, J. T. Kelly, A. M. Wright, N. I. Hammer and G. S. Tschumper, J. Phys. Chem. A, 2017, 121, 5884-5893.

9 K. P. Vijayalakshmi and C. H. Suresh, J. Phys. Chem. A, 2017, 121, 2704-2714.

10 P. L. A. Popelier, J. Phys. Chem. A, 1998, 102, 1873-1878.

11 F. H. Stephens, V. Pons and R. Tom Baker, Dalton Trans., 2007, 2613.

12 D. J. Wolstenholme, K. T. Traboulsee, Y. Hua, L. A. Calhoun and G. S. McGrady, Chem. Commun., 2012, 48, 2597.

13 A. D. Sutton, B. L. Davis, K. X. Bhattacharyya, B. D. Ellis, J. C. Gordon and P. P. Power, Chem. Commun., 2010, 46, 148-149.

14 A. D. Sutton, A. K. Burrell, D. A. Dixon, E. B. Garner, J. C. Gordon, T. Nakagawa, K. C. Ott, J. P. Robinson and M. Vasiliu, Science, 2011, 331, 1426-1429.

15 C. Reller and F. O. R. L. Mertens, Angew. Chem., Int. Ed., 2012, 51, 11731-11735. 
16 Y. Tan, L. Zhang, X. Chen and X. Yu, Dalton Trans., 2015, 44, 753-757.

17 O. T. Summerscales and J. C. Gordon, Dalton Trans., 2013, 42, 10075.

18 B. L. Davis, B. D. Rekken, R. Michalczyk, E. B. Garner, III, D. A. Dixon, H. Kalviri, R. T. Baker and D. L. Thorn, Chem. Commun., 2013, 49, 9095.

19 C. H. Giammanco, P. L. Kramer and M. D. Fayer, J. Phys. Chem. B, 2015, 119, 3546-3559.

20 R. Custelcean and J. E. Jackson, Chem. Rev., 2001, 101, 1963-1980.

21 R. Hayes, S. Imberti, G. G. Warr and R. Atkin, Angew. Chem., Int. Ed., 2013, 52, 4623-4627.

22 R. Hayes, S. A. Bernard, S. Imberti, G. G. Warr and R. Atkin, J. Phys. Chem. C, 2014, 118, 21215-21225.

23 R. J. Gillams, J. V. Busto, S. Busch, F. M. Goñi, C. D. Lorenz and S. E. McLain, J. Phys. Chem. B, 2015, 119, 128-139.

24 A. J. Johnston, Y. R. Zhang, S. Busch, L. C. Pardo, S. Imberti and S. E. McLain, J. Phys. Chem. B, 2015, 119, 5979-5987.

25 H. J. Jiang, S. Imberti, R. Atkin and G. G. Warr, J. Phys. Chem. B, 2017, 121, 6610-6617.

26 D. T. Bowron and K. J. Edler, Langmuir, 2017, 33, 262-271.

27 M. Falkowska, D. T. Bowron, H. G. Manyar, C. Hardacre and T. G. A. Youngs, ChemPhysChem, 2016, 17, 2043-2055.

28 A. Soper, Chem. Phys., 1996, 202, 295-306.

29 A. Soper, Mol. Phys., 2001, 99, 1503-1516.

30 A. K. Soper, Phys. Rev. B: Condens. Matter Mater. Phys., 2005, 72, 104204.

31 I. J. Chen, D. Yin and A. D. MacKerell, J. Comput. Chem., 2002, 23, 199-213.
32 B. Zhong, L. Song, X. X. Huang, L. Xia and G. Wen, Phys. Scr., 2012, 86, 015606.

33 J. Gao, X. Xia and T. F. George, J. Phys. Chem., 1993, 97, 9241-9247.

34 W. L. Jorgensen, D. S. Maxwell and J. Tirado-Rives, J. Am. Chem. Soc., 1996, 118, 11225-11236.

35 R. C. Rizzo and W. L. Jorgensen, J. Am. Chem. Soc., 1999, 121, 4827-4836.

36 M. L. P. Price, D. Ostrovsky and W. L. Jorgensen, J. Comput. Chem., 2001, 22, 1340-1352.

37 E. K. Watkins and W. L. Jorgensen, J. Phys. Chem. A, 2001, 105, 4118-4125.

38 G. A. Kaminski, R. A. Friesner, J. Tirado-Rives and W. L. Jorgensen, J. Phys. Chem. B, 2001, 105, 6474-6487.

39 T. F. Headen, C. A. Howard, N. T. Skipper, M. A. Wilkinson, D. T. Bowron and A. K. Soper, J. Am. Chem. Soc., 2010, 132, 5735-5742.

40 A. Soper, Mol. Phys., 2009, 107, 1667-1684.

41 T. Richardson, S. de Gala, R. H. Crabtree and P. E. M. Siegbahn, J. Am. Chem. Soc., 1995, 117, 12875-12876.

42 M. A. Ricci, M. Nardone, F. P. Ricci, C. Andreani and A. K. Soper, J. Chem. Phys., 1995, 102, 7650-7655.

43 T. Kar and S. Scheiner, J. Chem. Phys., 2003, 119, 1473-1482.

44 P. V. Ramachandran and P. D. Gagare, Inorg. Chem., 2007, 46, 7810-7817.

45 C. Benmore and A. Soper, The SANDALS Manual, 1998.

46 A. K. Soper, GudrunN and GudrunX Manual, 2012.

47 A. K. Soper, ISRN Phys. Chem., 2013, 2013, 1-67.

48 T. G. A. Youngs, dlputils: Calculate Properties from Molecular Dynamics Trajectories, accessed July 2017, https:// www.projectaten.com/dlputils. 